\title{
Evaluation of the Ratio of Monocyte / HDL Cholesterol in Psoriasis Patients
}

\author{
Nazli Dizen Namdar (Corresponding author) \\ School of Medicine, Department of Dermatology, Kutahya Health Sciences University \\ 43100, Kutahya Turkey \\ E-mail: nazli.dizennamdar@ksbu.edu.tr \\ Inci Arikan \\ School of Medicine, Department of Public Health, Kutahya Health Sciences University \\ 43100, Kutahya Turkey \\ E-mail: inci.arikan@ksbu.edu.tr \\ Mehtap Kidir \\ Department of Dermatology, Acibadem Hospital \\ 34734, Istanbul Turkey \\ E-mail: mehtap.kidir@gmail.com \\ Fatma Emel Kocak \\ School of Medicine, Department of Biochemistry, Kutahya Health Sciences University \\ 43100, Kutahya Turkey \\ E-mail: femel.kocak@ksbu.edu.tr \\ Hasan Tak \\ Department of Dermatology, Davraz Yasam Hospital \\ 32300, Isparta Turkey \\ E-mail: htak70@yahoo.com \\ Gulben Sarici \\ Department of Dermatology, Anadolu Hospital \\ 43020, Kutahya Turkey \\ E-mail: gulbensarici@yahoo.com
}

\begin{abstract}
The present study aims to investigate the monocyte to high-density lipoprotein cholesterol ratio (MHR) for the psoriasis patients and the correlation between MHR and Psoriasis Area and Severity Index (PASI) score. This study consisted of 96 psoriasis patients and 64 healthy individuals. Clinical properties and PASI scores of the patient group were recorded. Serum CRP and MHR were evaluated in both groups. The level of MHR was significantly higher in psoriasis patients than the control group (p:0.001). A significant positive correlation between MHR and PASI scores of the patients were detected. Increased level of Serum CRP was observed in psoriasis patients but is not associated with the PASI score. Furthermore, MHR and CRP had statistically insignificant positive correlation. To conclude, our findings indicate that high MHR values are significantly and independently related to the presence of psoriasis. In addition, considering the findings, we think that MHR can be used as an indicator of the severity of the disease for psoriasis.
\end{abstract}

Keywords: Psoriasis, Monocyte to HDL ratio, PASI.

\section{Special Issue of Health Sciences}

DOI: $10.7176 / \mathrm{JSTR} / 6-03-22$ 


\section{Objective}

Psoriasis is a chronic inflammatory disease, characterized by erythematous, squamous papules and plaques. In the pathogenesis of psoriasis, systemic inflammation plays a crucial role and causes many inflammatory comorbidities, especially cardiovascular diseases (Balta ve ark. 2014).

Regarding their crucial role for the secretion of proinflammatory and prooxidant cytokines at the inflammation site, monocytes and macrophages are critically important cells (Canpolat ve ark. 2016, Ancuta ve ark. 2006). Besides, protecting endothelial cells against undesirable effects of LDL and preventing oxidation of LDL molecules, HDL proves both anti-inflammatory and antioxidant actions (Canpolat ve ark. 2016 - Parthasarathy ve ark. 1990)

Monocyte to HDL-C ratio (MHR) is an inexpensive and easily calculated index obtained from routine laboratory tests (Akboga ve ark. 2016). In recent studies, MHR has been described as a new marker in cardiovascular diseases. (Canpolat ve ark. 2016, Akboga ve ark. 2016, Kanbay ve ark. 2014).

As far as we know, there is no study in the literature evaluating the role of MHR in psoriasis patients. In our study, we compared the level of MHR between psoriasis patients and control group. We also analyzed a relationship between MHR and the severity of the disease. Our aim was to analyze the relation between MHR and psoriasis.

\section{Materials and methods}

\subsection{Study Group}

Our study included 96 patients who were followed up by the Dumlupınar University Medical Research Hospital dermatology outpatient clinic and 64 healthy controls that did not have any dermatological or systemic disease during the last month. All psoriasis patients were stable and had no history of systemic treatment for psoriasis during the last month. Demographic (age and gender), clinical characteristics (duration of illness, family history, joint and nail involvement), and chronic diseases (hypertension and/or diabetes mellitus) were recorded. Psoriasis Area and Severity Index (PASI) score is used to define the severity of the psoriasis. PASI total score was between 0 and 72 (Louden ve ark. 2004). The high scores obtained by the PASI method show the severity of the Psoriasis disease. All patients were evaluated by the same dermatologist, who also calculated all the PASI scores.

Patients with non-psoriatic dermatologic disease, acute infection, hematologic disease, autoimmune and inflammatory disease, malignancy, renal and/or renal insufficiency and corticosteroid and antiinflammatory treatment were excluded from the study.

We performed this study based on the Helsinki Declaration with approval of the Dumlupinar University Local Ethical Committee.

\subsection{Laboratory analysis}

All patients' and control group's blood samples were used for the measurement of triglyceride (TG), total serum cholesterol (TC), high-density lipoprotein (HDL) and low-density lipoprotein (LDL) cholesterol after fasting for 12 hours in the morning. The complete blood count were analyzed in tubes with EDTA. Monocyte count was calculated by using CBC differential analysis data. The MHR was calculated by dividing the monocyte count to the value of HDL. Using the nephelometric measurement, C-reactive protein was measured with the help of automatized analyzer (Beckman Coulter IMMAGE)

\subsection{Statistical analysis}

The statistical analyzes were realized using the Kolmogorov-Smirnov test for the normal distribution of data. In the comparison of the averages, Student's t test was considered for normal distribution-matched data, and Mann-Whitney U test was employed for non-normal distribution data. The relationship between continuous data was assessed by Spearman correlation test. $\mathrm{p} \leq 0.05$ was regarded as a significant level.

\section{Results}

In our study, 96 patients with psoriasis (44 males and 52 females) and 64 healthy control subjects (17 males, 47 females) were evaluated. The mean ages of the patient and control group were $37.7 \pm 15.6$ (1673 years) and $33.7 \pm 11.4$ (19-70 years), respectively (Table 1). The mean duration of disease in the patients was $9.5 \pm 8.9$ months (1-45 months) and the mean age at onset was $28.5 \pm 15.5$ (10-72 years). Of the patients, $38.5 \%$ had nail involvement, $4.2 \%$ joint involvement, $25 \%$ family history, and $27 \%$ Hypertension (HT) and / or Diabetes Mellitus (DM) (Table 2). The psoriasis patients were found to have significantly higher $\mathrm{Hb}$, Wbc, monocyte and CRP values than control group, while the HDL value was determined to be significantly lower in the psoriasis patients (Table 1). 
The MHR was significantly higher in the psoriasis patients than the control group (p: 0.001) (Figure 1). There was not significant difference among MHR and nail involvement, joint involvement, family history, and presence of HT and/or DM in psoriasis patients (Table 2).

Most of our patients $(96.9 \%$ ) had mild to moderate psoriasis (PASI <10). Among the PASI and MHR scores of the patients there was a significant positive correlation (Figure 2). There was no correlation between PASI scores and CRP. Furthermore, a statistically insignificant correlation was found between MHR and CRP (Figure 3).

Table 1. Comparison of some mean values in patient-control groups

\begin{tabular}{|c|c|c|c|c|c|}
\hline & Groups & $\mathrm{n}$ & Mean & $\begin{array}{c}\text { Standard } \\
\text { Deviation }\end{array}$ & $\mathrm{p}^{*}$ \\
\hline \multirow{2}{*}{ Age, years } & Control & 64 & 33.70 & 11.385 & \multirow{2}{*}{0.077} \\
\hline & psoriasis & 96 & 37.70 & 15.671 & \\
\hline \multirow{2}{*}{$\begin{array}{l}\text { Hemoglobin } \\
\text { (g/dL) }\end{array}$} & control & 64 & 13.694 & 1.7320 & \multirow{2}{*}{0.046} \\
\hline & psoriasis & 96 & 14.282 & 1.9500 & \\
\hline \multirow{2}{*}{$\begin{array}{l}\text { White blood cell } \\
\text { count, } / \mathrm{mm} 3\end{array}$} & control & 64 & 7.347 & 1.8910 & \multirow{2}{*}{0.023} \\
\hline & psoriasis & 96 & 8.086 & 2.1622 & \\
\hline \multirow{2}{*}{$\begin{array}{l}\text { Monocyte count } \\
(103 / \mathrm{mm} 3)\end{array}$} & control & 64 & .533 & .1681 & \multirow{2}{*}{0.016} \\
\hline & psoriasis & 96 & .653 & .4396 & \\
\hline \multirow{2}{*}{$\begin{array}{l}\text { Total plasma } \\
\text { cholesterol, } \\
\text { mg/dL }\end{array}$} & control & 64 & 183.28 & 37.567 & \multirow{2}{*}{0.560} \\
\hline & psoriasis & 96 & 179.68 & 39.208 & \\
\hline \multirow{2}{*}{$\mathrm{LDL}-\mathrm{C}, \mathrm{mg} / \mathrm{dL}$} & control & 64 & 112.06 & 30.402 & \multirow{2}{*}{0.355} \\
\hline & psoriasis & 96 & 107.44 & 31.702 & \\
\hline \multirow{2}{*}{$\mathrm{HDL}-\mathrm{C}, \mathrm{mg} / \mathrm{dL}$} & control & 64 & 49.90 & 10.793 & \multirow{2}{*}{0.007} \\
\hline & psoriasis & 96 & 45.16 & 10.808 & \\
\hline \multirow{2}{*}{$\begin{array}{l}\text { Triglycerides, } \\
\text { mg/dL }\end{array}$} & control & 64 & 114.05 & 92.213 & \multirow{2}{*}{0.134} \\
\hline & psoriasis & 96 & 135.49 & 81.714 & \\
\hline \multirow{2}{*}{ CRP (mg/L) } & control & 62 & 2.768 & 3.7808 & \multirow{2}{*}{0.000} \\
\hline & psoriasis & 89 & 8.399 & 7.6276 & \\
\hline
\end{tabular}

LDL-C: Low Density Lipoprotein-Cholesterol

HDL-C: High Density Lipoprotein-Cholesterol CRP: C-reactive protein

Table 2. Comparison of MHR in patient group with clinical variables.

\begin{tabular}{|l|c|c|c|c|}
\hline & & \multicolumn{2}{|c|}{ Monocyte/HDL } \\
\hline & $\mathrm{n}(\%)$ & Mean $(95 \% \mathrm{CI})$ & Median & $\mathrm{p}^{*}$ \\
\hline Nail involvement & $59(61.5)$ & $0.014(0.013-0.016)$ & 0.014 & \\
Absent & $37(38.5)$ & $0.016(0.012-0.021)$ & 0.015 & 0.331 \\
Present & $92(95.8)$ & $0.015(0.013-0.017)$ & 0.014 & \multirow{2}{*}{0.908} \\
\hline Joint involvement & $4(4.2)$ & $0.018(0.004-0.039)$ & 0.016 & \\
Absent & & & & \\
Present & $72(75.0)$ & $0.016(0.013-0.018)$ & 0.015 & \multirow{2}{*}{0.077} \\
Family history & $24(25.0)$ & $0.013(0.010-0.017)$ & 0.013 & \\
Present & & & & \\
\hline Chronic disease (HT, & & & & \\
DM) & $70(72.9)$ & $0.016(0.014-0.018)$ & 0.014 & 0.238 \\
Absent & $26(27.1)$ & $0.013(0.010-0.016)$ & 0.012 & \\
Present & &
\end{tabular}

* Mann-Whitney U test

HDL: High Density Lipoprotein 


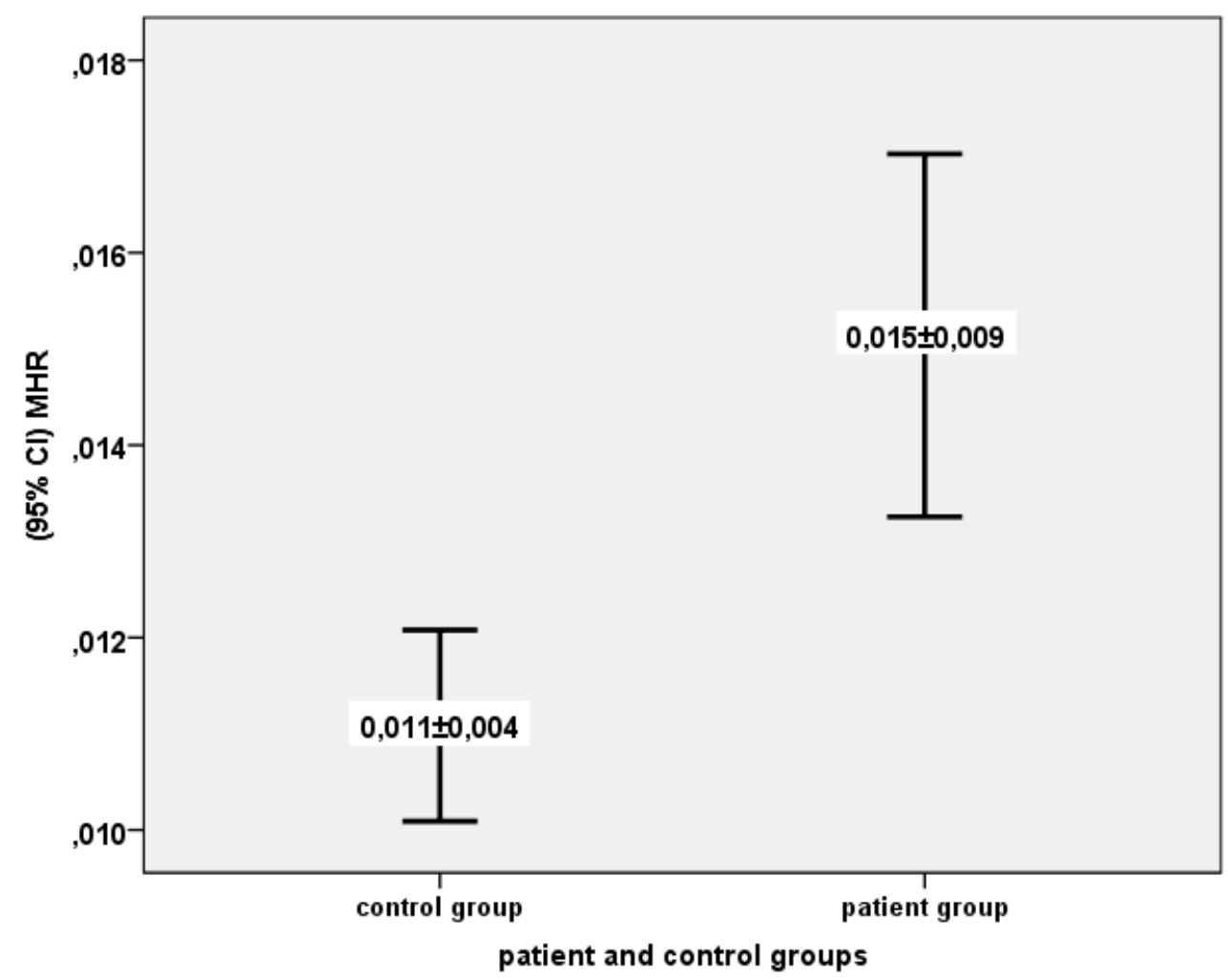

Figure 1. MHR averages and confidence intervals in the patient and control group $(\mathrm{p}=0.001)$.

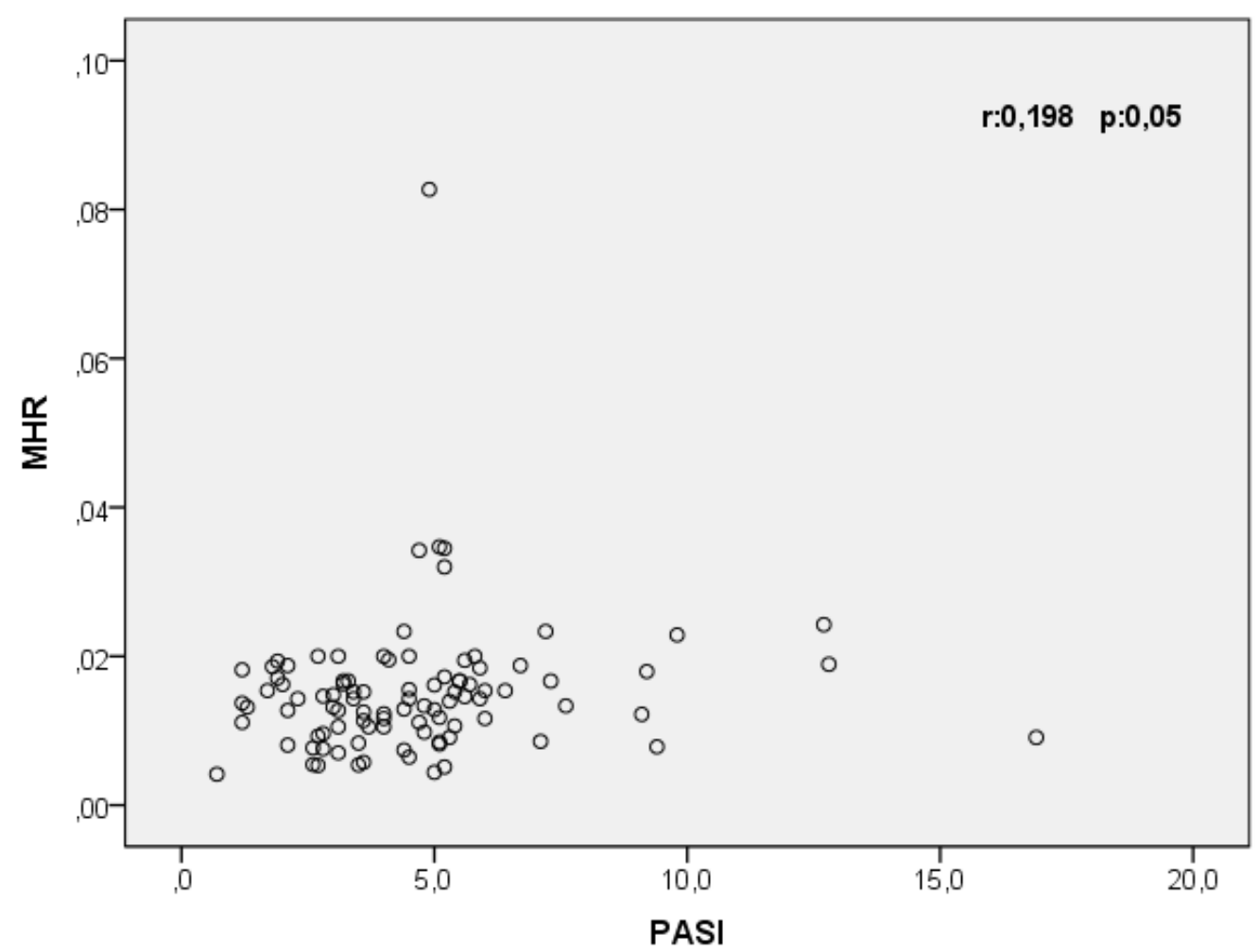

Figure 2. Correlation between MHR and PASI scores in patient group. 


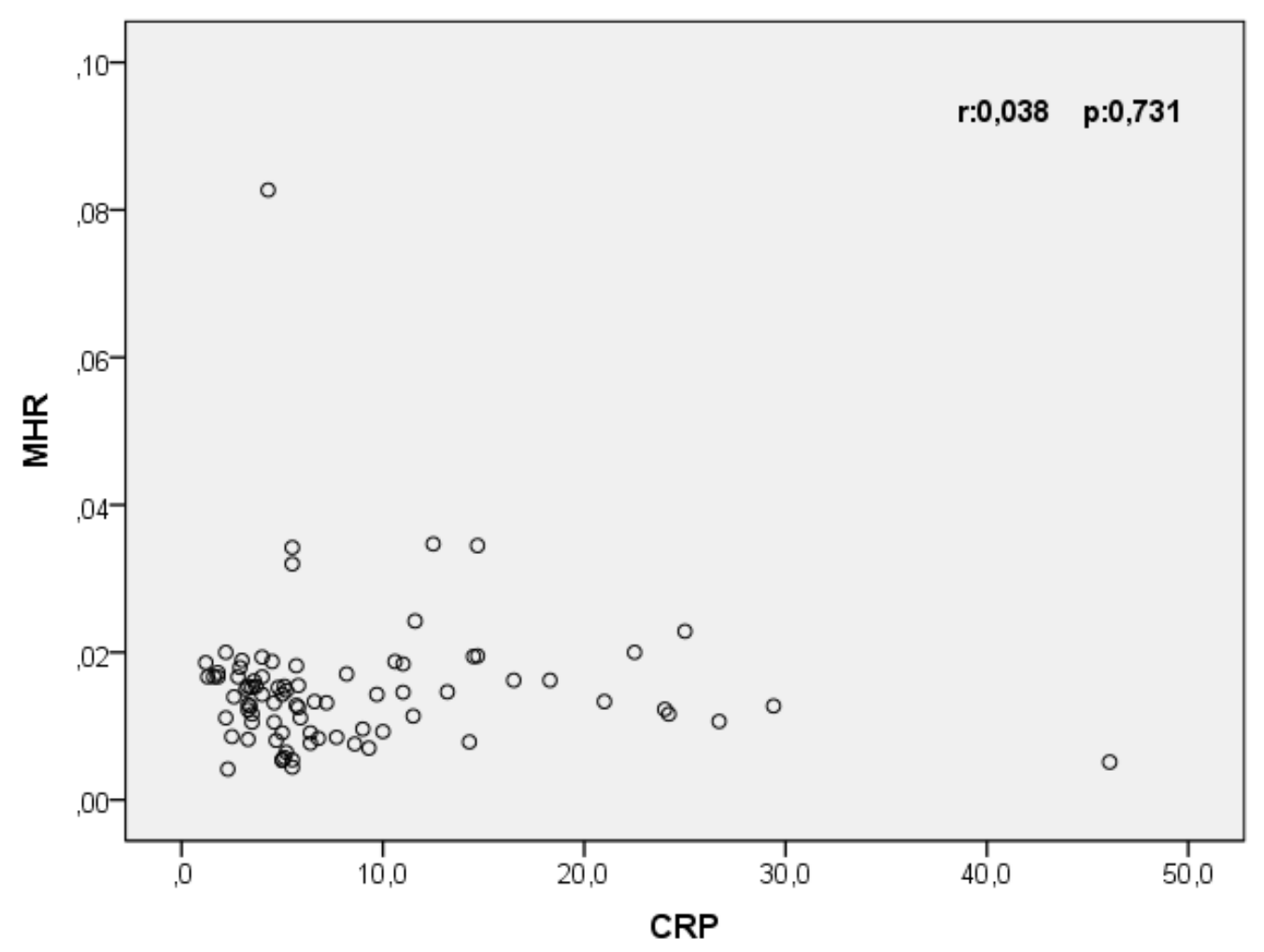

Figure 3. Correlation between MHR and CRP values in patient group.

\section{Discussion}

This study has revealed that MHR was significantly higher in psoriasis than the control group. Besides, a positive correlation was detected between MHR and PASI, which is recognized as an indicator of disease severity in psoriasis patients. Furthermore, the results show that MHR were significantly and independently related to psoriasis.

A number of studies are currently being conducted to find a suitable laboratory tool to evaluate the severity and progression of a long-standing psoriasis disease. Currently, PASI is used to evaluate the severity of the disease (Langley ve ark. 2004). But, it is not often used in everyday practice, because it is a time consuming method. In addition, due to its subjective nature, it can lead to personal differences even for experienced dermatologists (Langley ve ark. 2004- Sergeant ve ark. 2008). Therefore, an objective and reliable method is required.

The role of systemic pro-inflammatory cytokines was shown in the pathogenesis of psoriasis. Therefore inflammatory markers have been continuously investigated in order to obtain a qualified laboratory tool for evaluating the severity and progression of the disease (Strober ve ark. 2008- Beygi ve ark. 2014).

CRP is a biological marker of acute phase reactance and systemic inflammation (Strober ve ark. 2008). Some studies reported that CRP is elevated in psoriatic patients (Strober ve ark. 2008, Beygi ve ark. 2014, Takahashi ve ark. 2014). Some of these studies also reported that the elevated CRP level may act as a marker in assessing the severity of the disease (Strober ve ark. 2008, Beygi ve ark. 2014). In addition, Beygi et al. reported that CRP may function interchangeably with PASI as an indicator of disease severity for the moderate and severe psoriasis in untreated patients who do not have psoriatic arthritis as well (Beygi ve ark. 2014).

Other studies suggested that CRP and hs-CRP are not related to the severity of the disease in psoriatic patients (Sergeant ve ark. 2008, Takahashi ve ark. 2014). As in the studies of Takahashi et al., we found that CRP levels were high in patients with psoriasis, but we could not find a relationship between PASI score and CRP (Takahashi ve ark. 2014) When we consider all patients, we think that a new laboratory marker is needed to evaluate psoriasis severity.

In recent studies, MHR has been identified as a new potential marker for the detection of inflammation, and several studies have been conducted to predict clinical outcomes (Canpolat ve ark. 2016, Akboga ve ark. 2016, Kanbay ve ark. 2014, Balta ve ark. 2016, Kundi ve ark. 2015). To the best of the authors' knowledge, the relationship between psoriasis and MHR has not been investigated in any study to date. 
A study in slow coronary flow reported that MHR correlates positively with high sensitivity CRP (Canpolat ve ark. 2016). Akboğa et al. reported that among CRP and MHR, there was a positive correlation in stable coronary artery disease (Akboğa ve ark. 2016). In our study, a statistically insignificant positive correlation was seen between MHR and CRP.

In our study, there was no significant relationship between MHR and other symptoms of the disease such as nail involvement, joint involvement, family history, and chronic disease history in our psoriatic patients. We believe that more extensive studies should be carried out to determine the association of these values with MHR.

There were several limitations in our study: First, it had a cross-sectional design despite the fact that it is only a preliminary study investigating MHR levels in psoriasis. Second, the number of Psoriasis patients was small, and these observations must be confirmed in a larger sample of patients. Third, our study group mostly included mild to moderate severity psoriasis patients.

Finally, the findings of this study show that high MHR values are significantly and independently related with psoriasis. In addition, our study showed a significant correlation between MHR and PASI score, so we think that we can use MHR as an indicator of psoriasis severity. However, we believe that our findings should be supported by a wide range of prospective studies to illuminate the relation of the MHR with psoriasis.

\section{References}

Akboga, M. K. Balci, K. G. Maden, O. Ertem, A. G. Kirbas, O. Yayla, C. et al. (2016). Usefulness of monocyte to HDL-cholesterol ratio to predict high SYNTAX score in patients with stable coronary artery disease. Biomarkers in Medicine. 10(4), 375-383.

Ancuta, P. Wang, J. Gabuzda, D. (2006). CD16+ monocytes produce IL-6, CCL2, and matrix metalloproteinase-9 upon interaction with CX3CL1-expressing endothelial cells. J Leukoc Biol. 80(5), 1156-1164.

Balta, I. Balta, S. Demirkol, S. (2014). Cardiovascular comorbidities in patients with Psoriasis. Gulhane Tip Dergisi. 56, 61-63.

Balta, S. Celik, T. Ozturk, C. Kaya, M. G. Aparci, M. Yildirim, A. O. et al. (2016). The relation between monocyte to HDL ratio and no-reflow phenomenon in the patients with acute STsegment elevation myocardial infarction. Am. J. Emerg. Med. 34(8), 1542-1547.

Beygi, S. Lajevardi, V. Abedini, R. (2014). C-reactive protein in psoriasis: a review of the literature. Journal of the European Academy of Dermatology and Venereology. 28(6), 700-711.

Canpolat, U. Çetin, E. H. Cetin, S. Aydın, S. Akboga M. K. Yayla, C. et al. (2016). Association of monocyte-to-HDL cholesterol ratio with slow coronary flow is linked to systemic inflammation. Clin. Appl. Thromb. Hemost. 22(5), 476-82.

Hessler, J. R. Robertson, A. J. Chisolm, G. M. (1979). LDL-induced cytotoxicity and its inhibition by HDL in human vascular smooth muscle and endothelial cells in culture. Atherosclerosis. 32(3), 213-229.

Kanbay, M. Solak, Y. Unal, H. U. Kurt, Y. G. Cetinkaya, H. Karaman, M. et al. (2014). Monocyte count/HDL cholesterol ratio and cardiovascular events in patients with chronic kidney disease. Int. Urol. Nephrol. 46(8), 1619-1625.

Kundi, H. Gok, M. Kiziltunc, E. Cetin, M. Cicekoglu, H. Cetin, Z. G. et al. (2015). Relation between monocyte to high-density lipoprotein cholesterol ratio with presence and severity of isolated coronary artery ectasia. Am. J. Cardiol. 116(11), 1685-1689.

Langley, R. G. Ellis, C. N. (2004). Evaluating psoriasis with psoriasis area and severity index, psoriasis global assessment, and lattice system physician's global assessment. J. Am. Acad. Dermatol. 51(4), 563-9. 
Louden, B. A. Pearce, D. J. Lang, W. Feldman, S. R. (2004). A Simplified Psoriasis Area Severity Index (SPASI) for rating psoriasis severity in clinic patients. Dermatol Online J. 10(2), 7.

Lowes, M. A. Bowcock, A. M. Krueger, J. G. (2007). Pathogenesis and therapy of psoriasis. Nature. 445(7130), 866-73.

Nickoloff, B. J. (2007). Cracking the cytokine code in psoriasis. Nat. Med. 13(3), 242-4.

Parthasarathy, S. Barnett, J. Fong, L. G. (1990). High-density lipoprotein inhibits the oxidative modification of low-density lipoprotein. Biochim Biophys Acta. 1044(2), 275-283.

Po, L. W. (1999). Clinical measures of disease severity and outcome in psoriasis: a critical appraisal of their quality. Br. J. Dermatol. 141(2), 185-91.

Sergeant, A. Makrygeorgou, A. Chan, W. C. Thorrat, A. Burden, D. (2008). C-reactive protein in psoriasis. Br. J. Dermatol.; 158(2), 417-9.

Strober, B. Teller, C. Yamauchi, P. Miller, J. L. Hooper, M. Yang, Y. C. et al. (2008). Effects of etanercept on C-reactive protein levels in psoriasis and psoriatic arthritis. Br J Dermatol. 159(2), 322-30.

Takahashi, H. Iinuma, S. Honma, M. Iizuka, H. (2014). Increased serum C-reactive protein level in Japanese patients of psoriasis with cardio and cerebrovascular disease. J. Dermatol. 41(11), 9815. 